\title{
Development Status and Strategies on Rural Tourism of Jilin Province
}

\author{
Li-juan ZHANG ${ }^{1}$, Yan-wei WANG ${ }^{1}$, Jie $\mathrm{ZHAO}^{2}$ \\ ${ }^{1}$ School of economics and management, Northeast Dianli University, Jilin Province, China \\ ${ }^{2}$ School of law, Lilin University, Jilin Province, China \\ zhanglijuannedu@163.com,wangyanwei@nedu.edu.cn,626287052@qq.com
}

\begin{abstract}
Based on analysis of the development of rural tourism in Jilin Province, it can be found that there are some strengthens and weakness in the process of rural tourism development, and there are both opportunities and challenges to its development in external environment. We should foster strengths and circumvent weaknesses in the process of the development of rural tourism of Jilin province and then adjust the develop measures to local conditions.
\end{abstract}

Index Terms - Jilin Province, Rural tourism, SWOT analysis

\section{Introduction}

Just as Shao Qiwei, director of the National Tourism Administration said, rural tourism is the main force of tourism development in China, it is also an important support to tourism transformation and upgrading. As Jilin province has beautiful rural pastoral scenery, superior conditions, rich resources endowed by nature and the huge rural tourism market space and potential demand, it has a good prospects for development. The rural area in Jilin Province is an ensemble of traditional tourist attractions such as the picturesque scenery and unique local customs and modern tourist resources such as the ecological surroundings and rustic escapes. To develop Jilin rural tourism, we have to get to know what it is like out there currently, that is, to get a clear picture of its strengths and weaknesses, as well as the challenges and threats.

\section{Strengths of the Rural Tourism Development in Jilin Province}

\section{A. Rich Rural Tourism Resources}

Accredited as one of the award winning regions for its eco-tourism in 2007, Jilin is traditionally an agricultural province, typical of agronomic and farm work in northern regions of China. The composite of processing of crops, farm products, use of farm land and farming tools, life of farmers and farming households, and the customs of local families residing in the countryside provides an affluent source of agricultural and rural tourism. Tourist destinations o Changchun. Jilin, and Changbai Mountain are abundant with hot springs and ski fields, which are huge magnets for tourist across the nation. Moreover, 34 of the ethical minorities residing regions in Jilin Province have reserved the comparatively complete ethical practices and culture, and the food, clothing, festive activities are distinctively characterized with the life style of local ethnical residents.

\section{B. Rapid Development of Transportation}

The public transportation system in Jilin Province is undergoing a rapid development in recent years. Firstly, in regard of railway system, the Changchun-Jilin intercity railroad is launched in 2010, making it the fastest railroad in the northeast region of China, and the Harbin-Dalian high speed train that runs through Jilin Province took its first trip in 2012. Secondly, in terms of highways, the total highway traffic mileage in Jilin is 2326 kilometers up to 2013. Thirdly, in terms of air transportation, it is anticipated that by 2015 Jilin will have achieved the plan of building five airports with one serving as the major transport and transfer center and the other four as secondary centers. The major airport is the Changchun Longjia Airport, and the others are Yanji, Changbaishan, Tonghua, and Songyuan airports. Fourly, in regard of water transportation, the inland water ways in Jilin is up to 1789 kilometers.

\section{The Development of Rural Tourism and Its Products}

Currently, Jilin Province has more than 300 tourist destinations and attractions, 70 percent of which are located in countryside. With the phenomenal sensation of "Jilin-based TV shows", a bundle of TV shows were directed in Jilin Province, and among them, Shengshui Hun Pan, Cha Shu Ling, and some other shows featuring rural life have been played on China Central TV, the most influential state-owned TV station across the nation. The shooting locations of those shows have transformed into new tourist attractions. Further, a variety of rural tourism and local festive celebrations such as Ice and Snow Festival of Chanbai Mountain, Red Leaves Valley Festival of Jiaohe, Silver Birch Festival of Huadian, are of great magnet to tourists home and abroad. Hunchun and Ji'an in Jilin have been elected the model county/city for nationwide recreational agriculture and rural tourism.

\section{Weaknesses of the Rural Tourism Development in Jilin Province}

\section{A. Lack in Overall Planning}

Although the rural tourism in Jilin develops fast in recent years, the dearth of variety raises a serious issue. The services in these tourist attractions are much alike, and the overall planning of rural tourism does not suffice. This may be credited to two causes: One of the two is the lack of government-anchored overall planning and the professionals 
that are adequately garnished with the knowledge of managing and advertising rural tourism. The other is that the business people that actually run rural tourism do not have strong awareness of marketing, and do not take initiatives to promote and propagate themselves.

\section{B. Low level of Rural Tourism Reception}

In regard of facilities, only the tourism facilities of the model tourist destinations in Changchun, Tonghua, Jilin, and Songyuan are comparatively well supplied, but this number accounts for no more than one tenth of the total tourist accommodation among the more than 200 rural tourist attractions within the province. The majority of the destinations are not replete with their facilities. Also, in terms of reception, accommodation, transportation, shopping and entertainment require further amelioration.

In terms of services, the service personnel in rural tourism are mostly local and hence narrow-minded and shortsighted. They do not have the necessary professional training. They may charge tourists at will and soliciting is common. Service procedures are not rigid. in summation, the overall service still needs improving.

\section{Opportunities of the Rural Tourism Development in Jilin Province}

\section{A. The Macro Tourism Policy in Our Country}

China National Tourism Administration named Year 2006 as the Year of rural tourism, promoted in 2007 the concept of urban dwellers traveling to the countryside, and in 2010 signed the pact of advancing the development of recreational agriculture and rural tourism with ministry of agriculture. It was anticipated that from 2011, in three or five years, a bundle of model counties and villages might have been set up and a national network of recreational agriculture and rural tourism would have been established to provide for consumers quality rural tourism. In April, 2011, china national tourism administration designated may 19 th as the day of national tourism, which indicates an unprecedented opportunity for rural tourism.

\section{B. The Increase in Market Demand}

Most of the consumers of rural tourism are domestically based. With the progression of domestic economy and living standards, the accruement of paid vacation, the development of the resources of rural tourism and its products and the pleasant climate in rural areas and the pastoral scenery, rural tourism has become more urban dwellers' choice for recreation and vacation. In particular, with the improvement of living standards, cars are common to most households. Also, with the amelioration of rural transportation, self-drive traveling to the countryside has been one of the choices.

\section{The Infrastructure Investment Brought by the Revitalization of Northeast Old Industrial Base}

The tactics of revitalizing the northeastern provinces provides Jilin province more funds. In the course of developing and revitalizing the northeastern regions, Jilin invested a lot in basic facilities, such as the planning of Harbin -Dalian railway, Hegang-Dalian national highway, DaqingGuangdong national highway. In 2012, jilin government invested 3,750 million in road construction in rural areas with the aim that in 2013 all the qualified villages would be paved with cement roads. Such plans create an opportunity for the development of Jilin transportation and also will benefit the development of rural tourism.

\section{Threats of the Rural Tourism Development in Jilin Province}

\section{A. Fierce Industry Competition}

The provincial and civic governments have realized the driving force behind tourism industry to economic development, and thus strengthen the extent of developing and promoting the tourism products, and rival for the market. The rural tourism in Jilin province is confronted with ferocious completion from both within and without the province. For instance, the abundant resources of ice and snow in Heilongjiang, cultural tourism of man in Liaoning, pastor tourism in Neimenggu and the river tour in the southern provinces that have attracted a large population of tourists annually are the strong rivals of Jilin tourism

\section{B. The Diversity and Complexity of Tourism Demand}

With the rapid development of tourism market, sightseeing cannot satisfy people's desire for rural tourism; instead people direct more of their attention to more substantiated touring plan. Taking rural meals, fishing, singing, card games cannot no longer meet people' requirement, so more diverse tourism products are required. Otherwise, it is difficult to adapt to the tourism market's increasingly differentiating, complex and diverse needs.

\section{The Strategies of the Rural Tourism Development in Jilin Province}

From the developed countries' experience in rural tourism and combing it with the actual status of Jilin tourism, we are able to put forward the strategic choice for developing Jilin rural tourism.

\section{A. Strengthen the Protection of Rural Tourism Resources}

To maintain the sustainable development of rural tourism resources means to reinforce the protection of environment and tourism resources. Protection is multileveled. The government should increase the environmental awareness. For those industrial projects that are potentially hazardous to environment, the government should be farsighted and call out or disapprove of those projects. In addition, the government should invest more efforts in working the regulations on environmental protection. Also, to apply for historical heritage, national forestry parks, national sanctions will also do the same work. For instance, since the designation of the Goguryeo kingdom and the royal tombs as world heritage, not only the protection of local heritage has been strengthened, but the fame of the city also arises, which in turn stimulate $s$ and 
increase $s$ the local tourism economy to a great extent. Further, after he eagle-taming of Manchus, Paper-cutting and folk dancing of Korean ethnicity have been named as world heritage, not only the local culture will be handed down, but also it increase the local tourism income. Apart from the government's dominating role, environmental education to the tourists and local residents in particular is also essential.

\section{B. Suit Measures to Local Conditions to Develop Special Tourism Products}

Live on what is available, as the Chinese saying goes. Jilin has rich water resources. Heavenly Lake, the biggest volcano lake in china holds the Guinness world record for the volcano lake in the highest altitude. Jilin also has a large number of rivers and lakes and also dammed lakes. Songhua river, Liao rive, Yalu river and Tumen river and also Longwan national wetland resort, one of the ten wetland in china are all located in Jilin. Besides, endowed with scenery landscaping, Changbai mount is famed as the best mountain to the east of Shanhai pass. Jilin also resides many ethnical minorities. Songyuan has many Mongolia folk village, Yanbian has many Korean folk village, Jilin city has many Manchu folk village. We should be flexible to develop these rich tourism resources to make most use of them. Through the design of a well-chosen touring route, a overarching network of rural tourism system will be formed. We should reinforce the development of participatory and experiential tourism products to accentuate local distinctiveness and hence develop distinctive rural tourism.

\section{Strengthen the Macro Management of Rural Tourism}

Tourism is a broad and stimulating industry. How the government administers it at the macro level is crucial to the development of regional rural tourism. With the expansion of rural tourism, we should establish a government led Jilin Province Rural Tourism Association to administer and coordinate the affairs that are pertinent to the rural tourism within Jilin province and those that involve other provinces. Set up the management regulation and criterion for assessment and provide information inquiry services and training services for rural tourism practitioners. Meantime, the government should be the enactor of the environmental protection regulations and advocate of environmental protection.

\section{Focus on Brand Building and Promotion}

Rural tourism should focus on brand building, look on the government as a guide, multi-party participate, strengthen cooperation and joint promotion between urban and rural areas, attaches great importance to the construction of the rural tourism information network. First is strengthening the infrastructure construction around the scenic area, including traffic, accommodation, entertainment and shopping, etc. Secondly, we should apply for registration and brand protection promptly for the incoming brand. At the same time, extend the brand culture to various fields incisively to form a brand system which can promote and support each other. Again, develop tourism souvenirs vigorously and then propagandize it while selling it. Finally, increase the brand advocacy by using the different media.

Of course, the successful implementation of development strategies needs a perfect the system and coordination among the different department. View from the management system involving many fields, such as land, agriculture,water conservancy,environment, health, empl oyment, industry and commerce, taxation, tourism etc., all departments should formulate or follow the laws and regulations and perform their duties and coordinate with each other.

\section{Conclusion}

Used by the SWOT analytic method, It can be found that there are many strengthens and weakness in developing rural tourism in Jilin Province and there are both opportunities and challenges to its development in external environment after analyzed the current development situation of rural tourism. The government of Jilin province should update the concept, Jilin Tourism Bureau and the Jilin Provincial Commission and other relevant departments should actively manage and guide the investors to carry on the market analysis and development planning careful so that avoid to repeat construction. They should combine with the local government and act together, exert the rural tourism potential to the full, promote the development of rural tourism, improve farmers 'income and build a new socialist countryside.

\section{Acknowledgement}

This paper was financially supported by Jilin social science foundation, China grant \#2013B019 and Scientific research foundation of the education department of Jilin province, China grant 2013\# 91.

\section{References}

[1] D. Y and X. Z. Yu, "SWOT analysis on the development of rural tourism and its strategies in Liaoning Province," China Business \& Trade, no. 25, pp. 194-195, 2010.

[2] Q. Zhang and Z. W. Chen, "The Rural Tour and the Development of the Rural Tour of Jilin Province," Jilin Normal University Journal (Natural Science Edition), no. 11, pp. 29-31, 2003.

[3] J. Y. Chen and S. S. Lv, "Countermeasures on the developing of ecotourism in Jilin Province," Journal of Changchun Institute of Technology(Social Sciences Edition), no. 03, pp. 63-65, 2009.

[4] C. L. Zhang, "Development strategies and SWOT analysis on rural tourism of China," Commercial Times, no. 19, pp, 94-95, 2008.

[5] P. Hu, "SWOT analysis on the development of rural tourism in Heilongjiang province," Heilongjiang Social Sciences, no.5, pp.62-64, 2011.

[6] S. Guo, "Development status and strategies on snow sport tourism of Jilin city," China Business \& Trade, no. 12, pp. 172-173, 2011. 